\title{
An Assessment of Risk Management in Joint Venture Projects (JV) in Malaysia
}

\author{
Hamimah Adnan \\ Department of Quantity Surveying \\ Faculty of Architecture, Planning \& Surveying \\ University Teknologi Mara \\ 40450 Shah Alam, Selangor \\ Malaysia \\ E-mail: hamimah_uitm@yahoo.com.my
}

\begin{abstract}
Construction joint ventures have attracted a lot of research interest over the last two decades. Joint venturing can allow participating companies to rapidly change the scale or scope of their businesses. However, joint ventures are often regarded as a risky business. The construction industry is associated with high degrees of risk in the nature of its business activities, operational environment and organization. The success of a construction project depends on the results it is supposed to achieve. But achieving results depends upon how well companies manage the risks that confront their projects.

This paper aims to identify the risk factors associated with joint venture projects in the Malaysian construction industry at the project-specific, internal and external levels. The main factors crucial to joint venture success were identified from a literature review and through a questionnaire survey administered to both local and foreign construction organisations in Malaysia. The major risks factors were found to be the agreement of the contract, partner selection, control/equity, sub-contractors, renegotiations and training. The identification of these factors will assist the successful application of joint venture arrangements in construction projects in Malaysia and other similar economies. The major risks factors were found to be the agreement of the contract, partner selection, control/equity, sub-contractors, renegotiations and training.
\end{abstract}

Keywords: Risk management, Construction, Joint ventures

\section{Introduction}

A joint venture is a procedure used to respond to specific business phenomena such as access to new markets, specific government policy, business capacity, technology transfer or economies of scale. An international joint venture is a separate legal organisational entity representing the partial holdings of two or more parent firms, in which the headquarters of at least one is located outside the country of operation of the joint venture. The feasibility and the desirability of a joint venture must be assembled by careful analysis of the economic, political, social and cultural environment within which the venture will be implemented and managed. A planned approach necessitates a thorough and careful evaluation of these aspects by both partners to ensure successful implementation. Risk management techniques are not so well developed in the construction industry and there is a need to develop proven techniques, rather than rely on intuitive methods.

Construction organisations have used international joint ventures extensively as a vehicle to enter new construction markets around the world (Mohamed, 2002). The number of international construction joint ventures is growing worldwide at an increasing pace, especially in developing countries (Lim and Liu, 2001). The increasing magnitude, complexities and risks associated with major construction projects have brought together organisations with diverse strengths and weaknesses to form joint ventures to collectively bid and execute projects (Kumarasawamy, et.al.2000).

\section{Problem Statement}

In Malaysia, there are a number of different combinations of Malaysian contractors and local partners and also Malaysian contractors with foreign partners. Also, these projects vary in type, scale and complexity. There is need, firstly to map out the range of variables then to select a suitable set of comparable JVs for further in deep limitations. 


\section{Objective of the Research}

The main objective of this research was to determine the most critical risk factors which support the successful application of joint venture arrangements in construction projects in Malaysia. The result of this study are expected to provide useful guidelines for forming and operating effective and efficient joint ventures both in Malaysia in other similar economies.

\section{Overview of Risk Management in the Construction Industry}

The construction industry is one of the most dynamic, risky, challenging and rewarding fields (Mills, 2001). As any other major sectors, the construction industry is exposed to a lot of predictable and unpredictable risks. Among the risks faced by the construction industry are political risk, economic risk, technology risk and social risk. Risk is inherent in every construction project and normally assumed by the owner unless it is transferred to or assumed by another party for fair compensation. The principle guideline in determining whether a risk should be transferred is whether the receiving party has both the competence to fairly access the risk and the expertise to control or minimize it.

According to Mills (2001), risk management has become a main part in the decision making process. It can affect productivity, performance, quality and the budget of a construction project. The goal behind the risk management process is to obtain understanding by all parties and agreement around what the risks really are and how they will be managed. Apart from that, it is also intended to improve project to performance through early risk identification, mitigation and project life cycle management. Uncertainty can be regarded as the chance of occurrence of some events or events where the probability distribution is genuinely not known. Risk exists when a decision is expressed in terms of a range of possible outcomes and when known probabilities can be attached to the outcomes.

Risk management applied to the construction industry refers to the assessment and reaction to the risk and uncertainty that will inevitably be associated with a project. To manage a project, a system to control cost, quality of time and safety are normally employed in order to meet the objectives and expectations of a company. Risk management is the systematic process of identifying, analyzing, mitigating or responding to potential project risk. It includes maximizing the probability and impact of positive events and minimizing the probability and consequences of events adverse to project objectives. Because of the complex nature of construction business activity processes, environment, and organization, the participants are actively exposed to a high degree of risk. Construction involves unforeseen and predictable risks (Smith, 1992). Predictable risks are events or conditions that the contractor can foresee before construction begins. In the Malaysian construction industry, risk management is one of the new management concepts. It will take a long time to be fully accepted by the participants in this industry. Most of them are reluctant to change, they are still comfortable with their traditional culture in doing their job without realizing that this new concept will make their job easier.

To create sustainable value in today's dynamic environment, considerations of risk and opportunity have become imperative in business management. Risk management that emphasizes on proactive measures provides contingency planning and will enhance the achievement of the projects aims and objectives. Flanagan (1995) argued that, the individuals involved in the construction industry that undertakes various activities are heterogeneous since client, consultants and contractors have different roles and objectives. Flanagan (1995) further explained that the principals or the client could easily see the relevance of risk management when making the decision to commission a project. The decision to commence a project or invest in a project involves a lot of risks in terms of cost benefit or cash revenue, which is competitive with the best that the financial market can provide.

Other parties in the construction team such as consultants, contractors, subcontractors and supplier are also exposed the risks. This statement is supported by Sawczuk (1996), who he stressed that no matter how small or simple the project is, it still can go wrong, as soon as the two parties; the client and the contractor have signed a contract, they have taken onboard the risks. Risk awareness is of paramount importance to all participants to ensure that the possible risk occurrence is reduced.

In the Malaysian construction industry, risk management is one of the new management concepts. It will take a long time to be fully accepted by the participants in this industry. Most of them are reluctant to change; they are still comfortable with their traditional culture in doing their job without realizing that this new concept will make their job easier.

Due to the rapid pace of changing technology, inflation and the new problems of energy and environment, risk management is a management tool that the construction industry cannot afford to be without. However, this awareness among the Malaysian construction industry's participants is still low. However, no one can deny that there are the companies in this industry which practice risk management in their daily operation. However, we can only see this culture in big companies which have a very good reputation, strong financial standing and which are involved in projects. 


\section{Construction joint venture projects in Malaysia}

The Construction industry plays a vital role in our country's economic growth. It has contributed to the Gross Domestic Product (GDP) of the country and can be the indicator or yardstick of the country's economic performance. First, is the general construction, which comprises residential construction, non-residential construction and civil engineering construction. Meanwhile the second area deals with special trade works, which comprises activities such as metal works, electrical works, plumbing and services, carpentry, tiling, flooring works and glasswork.

Although it accounts for less than 5 percent of the GDP, the industry is a strong growth push because of its extensive linkages with the other economic sectors. No doubt, the construction industry is an important contributor to Malaysia's growth. It includes activities ranging from constructing building, roads, electricity or other transmission lines or towers, pipelines, oil refinery to other specific civil engineering projects. The Malaysian construction industry is a conglomeration of diverse sub-industries loosely lumped together as a sector of the economy. The industry is primarily concerned with building and civil engineering, and its main activities relate to the planning, regulation, design, manufacturing, construction, fabrication and maintenance of buildings, infrastructure facilities and process plant. The building sector of the industry encompasses the construction of commercial, industrial and housing (high, medium and low-cost) projects; infrastructure facilities includes the construction of roads and highways, drainage, sewerage, industrial structures, dams and water retaining structure projects; whilst process process-plant construction ranges from sewerage, water treatment, energy to fertilizer and food projects. The scale of construction projects may vary from work worth a few hundred Ringgit to major schemes costing several billion Ringgit. This includes everything from house repair to large and sophisticated civil engineering projects such as the Kuala Lumpur City Centre (KLCC), Kuala Lumpur Tower, Express Rail Link (ERL), Penang Bridge and the Kuala Lumpur International Airport (KLIA).

Over $65 \%$ of the volume of construction work within the industry comprises of infrastructure and civil engineering works whilst the balance is building and maintenance works. There are approximately 60,000 local construction firms within the industry, but only about 20,000 are active. Malaysia is one of the leading countries in South East Asia involved in international contracting and CIDB reports that Malaysian companies are participating in a variety of construction projects in over 30 countries (CIDB, 2005). These firms have since undertaken a few mega projects overseas which include expressways, buildings, electric power stations, bridges and others. However, within the global context, leading international companies such as Japan's Taisei, Shimizu and Kajima Corporations, France's Bouygues, and Bechtel of the US dwarfs these companies.

The Malaysian construction industry is the fourth largest employer of the Malaysian workforce. It is heavily craft-based and employment within the industry fluctuates significantly with the boom and bust cycles. On the average, the construction industry employs over 800,000 people or about $8 \%$ of the total workforce. In addition to this, there are thousands other people employed in the administrative, professional, technical and clerical occupations, but there has been no official record to ascertain their numbers accurately.

Construction is included in the General Agreement on Trade in Services (GATS). Foreign construction companies are encouraged to take up stakes in construction and infrastructure projects together with local companies. They are treated as local contractors unless their stake in a Malaysia company exceeds $30 \%$, or if the company is a $100 \%$ incorporated in the country of origin. Malaysia is also a signatory of the ASEAN Framework Agreement on Services (AFAS) whose objective is to promote economic cooperation and improvements in the economic delivery system. This is also support the ASEAN VISION 2020, which aims to promote better free flow of trade between the ASEAN countries. In parallel with its GATTS commitments, Malaysia has significantly lowered the restrictions on the establishment and operation of a commercial presence by foreign firms from ASEAN countries from $30 \%$ to $40 \%$.

The "Look East Policy" introduced in the early 1980s that carried through until the late 1990s, further encouraged foreign contractors to participate in the industry, with those from the United Kingdom, Japan and South Korea most active (Adnan 2004). Since rebounding from the economic recession in 1997, the number of foreign contractors in Malaysia has been increasing with most of the contractors from Korea, Japan, Singapore, Germany, UK and other European countries. With stricter regulations, joint-ventures offer the main alternative route into the Malaysian construction market. The government is now looking at more local-foreign joint ventures to participate in the regional and global market.

The slowdown in award of contracts by the Government has spurred many construction companies, in particular the larger ones, to venture abroad in search of greener pastures. India and the Middle East are the popular, accounting for about half of the overseas projects, particularly India where Malaysian companies have completed 39 projects worth RM5.7 billion and are reported to have a market share of $25 \%$ of the infrastructure jobs awarded there.

Going forward, the implementation of construction projects under the Ninth Malaysia Plan (9MP) is expected to provide some impetus for growth in the construction sector. The budgeted expenditure under the $9 \mathrm{MP}$, spanning from 2006 to 2010, will be around RM150. The main thrust of the 9MP is on the development of human capital and the services industry. This is good indication that there will be more construction and upgrades of education centres, 
hospitals and tourist destinations as well as improvement of infrastructure facilities such as roads and bridges. The 9MP will also endeavor to gradually reduce the Government's budget deficit through exercising greater fiscal discipline or prudence to ensure that maximum benefits are obtained when selecting and implementing projects under the 9MP.

Due to limited resources, new projects that will be considered for the 9MP are projects that will generate multiple benefits for the nation. Among the criteria used will be human friendly projects whereby emphasis will be given to improving road safety and providing convenience for road users and projects which can save traveling cost and time. This will include construction and upgrading of roads to overcome traffic congestion in town centres as well as in new growth areas.

Joint ventures are established to take advantage of the economic, political and social conditions prevailing in a particular economy. In Malaysia's case, international firms came to its shores mainly because of its political stability, economic growth and a relatively low cost of labour and other resources. Construction joint ventures in Malaysian are becoming increasingly popular both in multinational construction firms and local government in order to achieve their individual objectives. There are already established joint ventures between two or more local indigenous contractors and also between indigenous local and foreign contractors.

In Malaysia's case, international firms were attracted to its shore mainly because of opportunities stemming from the country's planned economic growth, its political stability a relatively low cost of labour and other resources. Construction joint ventures in Malaysia are popular and have involved multinational construction firms and local government in order to achieve their individual objectives. The government for Malaysia has also encouraged and supported local contractors to participate in regional and global markets based on their expertise and experience of construction of buildings, infrastructure projects, highways, power generation, port and airport construction.

Foreign contractors were operating in Malaysia long before the signing of the GATS (Note 1) accord in January 1995. At that time, foreign firms were admitted mostly in a non-discriminate manner and there were no rigid trade-related sanctions on foreign-owned firms that were allowed to operate Malaysia's domestic market. Currently, the implementation of its commitments under the GATS, market access restrictions promulgated by Malaysian regulators have opened opportunities to foreign firms to operate through joint ventures with Malaysian individuals or institutions, both as local as well as foreign contractors.

Malaysia's booming economy and the Malaysian Government policy of becoming fully industrialised has spawned massive developments creating a conducive investment environment. Over the years, Malaysia has attracted a good deal of well-known multinational companies from Japan, Taiwan, Korea, United States, United Kingdom France, Australia, Germany, Canada, Denmark, India, South Africa and others. This included work for public and private clients comprising infrastructure, civil engineering works and residential development. These projects have included work for public and private clients comprising infrastructure, civil engineering works, residential and non-residential building work. Foreign firms are often required to bid with local partners on large infrastructure projects and a JV bid must normally have at least $30 \%$ bumiputera (indigenous Malay) participation.

The rapid expansion of construction activities following industrialisation programmes has intensified the participation of foreign contractors. Joint ventures with local contracting firms were encouraged. Major projects undertaken with foreign participation included Kuala Lumpur International Airport, the Petronas Twin Towers, Pergau Dam, the Multimedia Super Corridor and The Sepang Formula One Circuit.

The Malaysian Government's encouragement and incentives of such arrangements could also be considered as a significant factor in the development of joint venture projects. Foreign firms are often require to bid on large infrastructure projects with local partners and a joint venture bid must have at least $30 \%$ bumiputera (indigenous Malay) participation. Malaysia's open-door policy to foreign participation is evidenced by the large amount of payments made by the Malaysian Government for contracts and professional services.

Successful bidders for projects are predominantly established multinational corporations and the majority of contractors depend upon their special expertise to secure projects. Most of the projects are infrastructure projects or engineering and construction works for petroleum products processing plants. Lack of local expertise has been cited as one of the main reasons for the utilisation of foreign firms. In a large number of projects, sophisticated technology and know how are crucial to ensure successful completion. These projects provide excellent opportunities for Malaysian companies to combine and for foreign contractors to team up with Malaysian contractors to explore business opportunities.

These projects have included work for public and private clients comprising infrastructure, civil engineering works, residential and non-residential building work. Foreign firms are often required to bid with local partners on large infrastructure projects and a JV bid must normally have at least 30\% bumiputera (indigenous Malay) participation.

\section{Research Methodology}

The research methodology was divided into three major sections consisting of a literature review. questionnaire survey and in-depth interviews. The questionnaire survey was distributed to 550 Grade G7 and G6 registered contractors under the Construction Industry Development Board Malaysia (CIDB). The purposed of the questionnaire was to discover 
which companies had experience of JV projects, the extent of that experience and their views of risk factors associated with joint ventures.

The $2^{\text {nd }}$ part of the research involved a case study whereby an in-depth interview conducted with the General Manager of the Grade G7 contractors to provide detailed information on his company structure, management and experience of one of his major projects undertaken in Malaysia. It was found from the search for appropriate cases of JVs that those in this category were restricted. The search for cases such as JVs was made in the various company directories particularly in construction organisations such as the CIDB Malaysia, Master Builders Association Malaysia and Malaysia 2000 Construction Equipment and Builders' Directory.

\section{Results and Analyses}

There were fifty (50) local contractors and five (10) foreign contractors which responded to the questionnaire. This was about $10 \%$ of the total number of the 550 companies. Only 10 foreign companies returned the questionnaire out of 50 foreign companies and all was willing to be interviewed. This was disappointing but it was thought that it could be the lack of JV experience which could be the reason. It could be that there were many that had not been received, or it could be that those not responding had bad experiences in JVs, or they were reluctant to share their experience.

The questionnaire was divided into three parts:

Part One: General information about the JVs - company status, nature of business, involvement's in JVs project numbers and operation structure.

Part Two: Risk factors that might be involved in JV projects. These factors were divided into three groups, namely internal, project -specific and external risks (Groups 1,2 and 3).

Part Three: For companies with no experience of joint venturing but which were willing to participate in the future.

A Likert Scale of 1-5 was used in the questionnaire. The respondents were required to indicate the relative criticality/ effectiveness of each of the risk factors and management measures.

Most of the respondents were involved in the civil engineering works, which consisted of highways, roads and bridges, tunneling, road pavements and resurfacing. About $50 \%$ of them were involved in commercial, industrial and residential building. Many projects had been completed but some were still in progress. There were others involved in specialist works, piping, petrochemical and oil refinery and airport facilities.

From the questionnaire on the priority to be achieved from the JV projects was the new market opportunities where 19 respondents out of 40 agreed on the statement, which makes $51 \%$ from the overall population. Meanwhile, increasing project scale and profit were at 2 nd and $3^{\text {rd }}$ ranked which are $23 \%$ and a slight decrease in percentage to $22 \%$ of the respondent's priorities. This was followed by time of completion, cooperation and quality of works, which took the $4^{\text {th }}$ and $5^{\text {th }}$ places.

Since the construction markets in the developing countries are unfamiliar to most of the companies in developed countries. It is always difficult for them to get into the markets at the beginning. Joint venturing is one of the most common ways to overcome the barriers to these markets. By forming the JVs, foreign companies improved access to local human resources including managers and labour, and specific resources possessed by local partners. This capability is, therefore, improved in terms of size and scope of work undertaken.

From the research, the respondents ranked first business expansion and new economies of scale. The financial status for a company was at the $2^{\text {nd }}$ rank. It could be seen that the skill and experience, competitive advantages and market share were at the $3^{\text {rd }}$ rank. 13 respondents also shared their opinion of having technology, knowledge and information and sharing of risk. The new market opportunity and coordination of work were in the $5^{\text {th }}$ place and sharing of resources was in the $6^{\text {th }}$ place.

From the research survey, the writers concentrated on the risk factors that were involved in JV projects based upon the respective contractors' experience. The analysis assessed the 29 respondents that responded to the question on risk factors.

\subsection{Risk Group 1: Internal Risk Factors}

Among the nine factors, the highest mean of 3.89 was the problem from both the partner's parent companies. Another risk factor related to a partner is its lack of management competence and resourcefulness, which is ranked $2^{\text {nd }}$. Thus the credit worthiness of a prospective JV party's parent company should be scrutinized and its current management competence and resources must be ascertained. (Li Bing, Tiong 1999).

Policy changes received the $3^{\text {rd }}$ highest rank, which was at 3.29 and 3.25 , which is very critical among the internal risk factors for a JV project. The parent companies play an important role in the JV process as they can influence a JV's performance. Most of the researchers on JVs have concluded that a good JV agreement is an essential success factor and can avoid a great deal of trouble and conflict in future JV operations. 
Employment from the parent company and work allocation received $5^{\text {th }}$ and $6^{\text {th }}$ rankings; as trust among JV staff from different partners is also a critical risk factor in JV projects. Another critical risk factor is the disagreement on accounting of profit and loss. It received the $7^{\text {th }}$ ranking; followed by the technology transfer and disagreement on allocation of staff positions in JV which received less critical scores, ranking $8^{\text {th }}$ and $9^{\text {th }}$, respectively. Disputes over works allocation often happen when designs are changed and the changes are unfavourable to one of the partners. Technology transfer received the least critical ranking in this group.

Table 1. Internal Risk Factors

\begin{tabular}{|l|l|l|}
\hline No & Risk Factors & Mean \\
\hline 1. & Financial Problems & 3.89 \\
\hline 2. & Management & 3.44 \\
\hline 3. & Policy & 3.29 \\
\hline 4. & Over inteference & 3.25 \\
\hline 5. & Employment & 2.97 \\
\hline 6. & Allocation of work & 2.96 \\
\hline 7. & Accounting & 2.88 \\
\hline 8. & Technology Transfer & 2.77 \\
\hline 9. & Allocation of staff positions & 2.61 \\
\hline
\end{tabular}

\subsection{Risk Group 2: Project- Specific Factors}

The risk caused by the project characteristics must be considered when dealing with JVs risk. Many JVs are formed for a specific project, and the project's characteristics could strongly influence the JV's performance. A Client's cash problem is regarded as the most critical risk factors to a JV. It received 4.19 and is ranked first in this group among all risk factors considered in this research. Thus, it could be seen that the financial risk to the JV contractor includes whether the owner has sufficient funds to complete the project or has the availability of funds for progress payments. The most critical factor is a poor project relationship. It received a critical value at 3.54 and $2^{\text {nd }}$ in the project-specific risk group. Strained relationships will occur when someone goes directly to the Client without informing his counterpart, particularly when the matter concerns contractor-client reimbursement.

Currently, in the construction industries, the general contractors are subcontracting many project activities. It is rated as the $3^{\text {rd }}$ critical risk factor in the group. Compared with other risks, disagreement over some conditions in the contract is considered to be less critical value at 2.89. Contractual risks usually are caused by disagreement arising from flawed contract documents, inappropriate types of contract, improper tendering procedures, contractual clauses and/or incomplete contract documentation.

Table 2. Project Specific Factors

\begin{tabular}{|l|l|l|}
\hline No & Risk Factors & Mean \\
\hline 1 & Cash Flow Problems & 4.19 \\
\hline 2 & Poor Project & 3.54 \\
\hline 3 & Incompetence of suppliers & 3.08 \\
\hline 4. & Conditions of Contract & 2.89 \\
\hline 5. & Demands \& Variation By Client & 2.88 \\
\hline
\end{tabular}

\subsection{Risk Group 3: External Risk Factors}

The major risk factors for overseas construction projects at the national or regional level are those related to economic, political, social and environmental risks. Economic fluctuation and inflation score the highest means at 3.80 and 3.49. These were followed by policies, fund repatriations and exchange rate, which stand at the $3^{\text {rd }}, 4^{\text {th }}$ and $5^{\text {th }}$ ranking, respectively. Economic slowdown causes the construction market to shrink. Foreign exchange risks exist when the JV formally enters a contractual agreement as a contractor with the owner. Inconsistency in policies, regulation restrictions on fund repatriation and import restrictions were ranked at $6^{\text {th }}, 7^{\text {th }}$ and $8^{\text {th }}$ respectively.

The environment has a certain critical influence on JV projects. It received a critical value at 2.26 and is ranked $9^{\text {th }}$ in this group. The participants considered the pollution effect on a JV least critical. The surveys showed that the social environment problems are not critical and they are ranked at 10 th and $11^{\text {th }}$, respectively. The lack of complimentarity is caused by a failure to understand how cultural assumptions influence the development of the JV. 
Table 3. External Risk Factors

\begin{tabular}{|l|l|l|}
\hline No & Risk Factors & Mean \\
\hline 1. & Economies Fluctuation & 3.80 \\
\hline 2. & Inflation & 3.48 \\
\hline 3. & Policies, laws and regulations & 3.39 \\
\hline 4. & Exchange rate & 3.21 \\
\hline 5. & Fund Repatriation & 3.14 \\
\hline 6. & Import restrictions & 2.55 \\
\hline 7. & Force Majeure \& Social & 2.50 \\
\hline 8. & Security Problems & 2.45 \\
\hline 9. & Pollution & 2.26 \\
\hline 10. & Language Barrier & 2.21 \\
\hline 11. & Different social, culture \& religion & 2.10 \\
\hline
\end{tabular}

\section{Conclusions}

The questionnaire survey on the JV projects between Malaysia local and foreign contractors working in Malaysia showed that both perceived risk in construction as the likelihood of the potential completion of the project i.e. terms of cost, time and quality of performance. To minimize the chances of failure or underperformance of a JV, risk management techniques must be introduced into the construction industry. In order to manage them effectively, a comprehensive method for managing risk techniques must be introduced into the construction industry. Also in order to manage them effectively, a comprehensive method for managing risk during the construction process, particularly in the pre- contracting and contracting stages, should be applied. The major risks factors were found to be the agreement of the contract, partner selection, control/equity, sub-contractors, renegotiations and training. The nature of construction JVs and international JVs compared with other types of procurement may be different due to the fundamental intent of co-operation in the participants where large differences in cultural, political and social backgrounds exist. The findings of the research will hopefully support the more successful implementation of joint venture projects in other similar economies.

\section{References}

CIDB (2005). Construction Industry Master Plan for Malaysia (2005-2015). Construction Industry Development Board (CIDB), Kuala Lumpur, Malaysia

CIDB (2006). Round Table Consultative Forum for the Government Sector. Construction Industry Development Board, Kuala Lumpur, Malaysia

Flanagan (1995) Flanagan, R. \& Norman, G., (1997) Risk Management and Construction. Blackwell Science

Hamimah Adnan (2004). Joint Venture in Malaysian Construction Industry, Factors Critical to Success, Unpublished PhD Thesis, The Nottingham Trent University, UK

Kumarasawamy (2000). Kumaraswamy, M., Palaneeswaran, E., and Humphreys, P. (2000) Selection matters-in construction supply chain optimization. International Journal of Physical Distribution of Logistic Management, Volume 30, $\mathrm{Nr} 708$, pp. 661-680

Li Bing, L.K.Tiong (1999). Risk Management in International Construction Joint Ventures.Journal of Construction Engineering and Management, 121(4)

Lim, E.C \& Liu, Y., (2001). International Construction Joint Ventures as a Market Penetration Strategy -some case studies in developing countries. Proceeding of the $3^{\text {rd }}$ International Conference on Construction Project Management, Singapore, pp. 377-389

Mohamed (2002), Mohammad, S., (2002). Performance of International Construction Joint ventures: An Empirical Analysis, First International Conference Construction in the $21^{\text {st }}$ Century (CITC 2002), Miami, Florida, USA

Mills (2001). Mills, A. A Systematic Approach to Risk Management for Construction. Retrieved 15 October 2006 from http://www.emerald-library.com/ft.

Mohamed (2002)

Swaczuk, B (1996). Risk Avoidance for the Building team, E \& FN, Spon, London 
Smith, R.G Member, ASCE, Bohn, M.C (1992). Small to medium Contractor Contingency and Assumption of Risk. Journal of Construction Engineering and Management, March/April 101-108

\section{Notes}

Note 1. The General Agreement on Trade in Services (GATS) is one of the agreements of the World Trade Organisation (WTO). It was brought under the rules of the multilateral trading system at the conclusion of the Uruguay Round in 1994. The GATS came into force on 1 January 1995. 